\title{
Thrombin inhibition by dabigatran attenuates atherosclerosis in ApoE deficient mice
}

Simon Pingel ${ }^{1}$, Vedat Tiyerili ${ }^{1}$, Jens Mueller ${ }^{2}$, Nikos Werner ${ }^{1}$, Georg Nickenig ${ }^{1}$, Cornelius Mueller ${ }^{1}$

\begin{abstract}
${ }^{1}$ Medizinische Klinik und Poliklinik II, Universitätsklinikum, Bonn, Germany 2Institut für experimentelle Hämatologie und Transfusionsmedizin, Universitätsklinikum, Bonn, Germany
\end{abstract}

Submitted: 5 January 2013

Accepted: 9 February 2013

Arch Med Sci 2014; 10, 1: 154-160

DOI: $10.5114 /$ aoms.2014.40742

Copyright $\odot 2014$ Termedia \& Banach

\begin{abstract}
Introduction: Atherosclerosis is a chronic inflammatory disease characterized by endothelial cell damage, infiltration, proliferation and accumulation of macrophages, lymphocytes and transformed vascular smooth muscle cells within the vascular wall and procoagulation processes involving activation of plasmatic coagulation events and platelets. Numerous studies suggested a close interaction between thrombin action and atherogenesis, but possibly underlying mechanisms are multiple and specific treatment options were missing until now.
\end{abstract}

Material and methods: Atherosclerosis prone 12 weeks old $\mathrm{ApoE}^{-/-}$mice were fed a cholesterol rich diet for 4 weeks and were concomitantly treated orally with placebo or the thrombin inhibitor dabigatran $(1.2 \mathrm{~g} / \mathrm{kg} / \mathrm{day})$.

Results: The thrombin time (HEMOCLOT ${ }^{\circledR}$ ) was significant extended in dabigatran treated animals. Vascular oxidative stress was significantly reduced during thrombin inhibition, as assessed by L012 chemiluminescence in aortic segments $(212 \pm 84$ vs. $69 \pm 21 \mathrm{RLU} / \mathrm{s} / \mathrm{mg}$ dry weight, $p=0.048)$. Organ chamber experiments of isolated aortic rings showed that dabigatran treatment significantly improved endothelium-derived vasorelaxation $(p<0.001)$. Dabigatran treated mice developed less atherosclerotic lesions $(6.2 \pm 0.2 \%$ vs. $9 \pm 1.1 \%, p=0.037)$ and showed less infiltration of atherosclerotic lesions with macrophages ( $2.59 \pm 0.3 \%$ vs. $5.14 \pm 0.7 \%, p=0.0046)$, as determined by systematic histological and immunohistological analyses of the aortic root. Blood pressure, body weight and food intake were not altered by the treatment.

Conclusions: The thrombin inhibitor dabigatran reduces vascular oxidative stress and inflammation, improves endothelial function and decreases atherosclerosis in mice.

Key words: dabigatran, thrombin inhibition, atherosclerosis, endothelial function.

\section{Introduction}

Atherosclerosis is a chronic inflammatory disease characterized by endothelial cell damage, infiltration, proliferation and accumulation of macrophages, lymphocytes and transformed vascular smooth muscle cells within the vascular wall and procoagulation processes involving activation of plasmatic coagulation events and platelets [1, 2]. In addition, close interactions between inflammation and the coagulation system have been suggested. This affects cross talk between platelets and pro-inflammatory cells as well as coagulation proteins, many of which are expressed

\author{
Corresponding author: \\ Cornelius Müller \\ Medizinische Klinik \\ und Poliklinik II \\ Universitätsklinikum Bonn \\ 53105 Bonn, Germany \\ Phone: +49228 28751488 \\ Fax: +49 22828711271 \\ E-mail: cornelius.mueller@ \\ ukb.uni-bonn.de
}


in atherosclerotic lesions or have been shown to enhance vascular lesion progression [3-5].

Thrombin is one of the key players in the coagulation cascade [6, 7]. On one hand thrombin has been suggested to increase endothelial-dependent vasorelaxation and nitric oxide bioavailability $[8,9]$, while on the other hand thrombin may increase vascular inflammation, alter endothelial cell phenotype and decrease endothelial function, may cause contraction and proliferation of vascular smooth muscle cells and thereby accelerate atherogenesis $[6,10]$. The mode of action may depend on the vascular bed, the duration of action, species, state of atherosclerosis and many other so far unidentified conditions.

Due to the obvious interaction of coagulation and atherogenesis, therapeutic anticoagulation has been evaluated as an atheroprotective measure in the clinical arena $[11,12]$. Vitamin $\mathrm{K}$ antagonism led in patients with peripheral artery disease or patients after myocardial infarction to mostly moderately reduced cardiovascular event rates at the cost of excessive bleeding rates. Based on this rather modest net clinical benefit, the notorious difficulty to achieve target anticoagulation levels, and the requirement of treatment monitoring, the use of this strategy in routine practice is limited. The possibility to specifically address the key player thrombin with an easy to apply treatment option, such as the novel oral thrombin antagonists, revitalized the question whether atherosclerosis and subsequent events can be inhibited by anticoagulation [13].

In order to decipher a causal relationship between thrombin antagonism and atheroprotection and in order to gain insight into the underlying mechanisms, we evaluated the effect of an oral thrombin antagonist on atherosclerosis in ApoE $\mathrm{E}^{-/-}$mice.

\section{Material and methods}

Western diet containing dabigatran $(10 \mathrm{mg} / \mathrm{g})$ was kindly provided by Boehringer-Ingelheim. All other chemicals were purchased from Sigma (Deisenhofen).

\section{Animal experiments}

12 weeks old $\mathrm{ApoE}^{-/-}$mice were fed with Western diet containing no additive or dabigatran $(10 \mathrm{mg} / \mathrm{g})$ for 4 weeks. Afterwards the mice were sacrificed and the aortas excised. The vessel was then immersed in chilled buffer containing (in $\mathrm{mmol} / \mathrm{l}) \mathrm{NaCl} 118.0, \mathrm{CaCl}_{2}$ 2.5, $\mathrm{KCl} 4.73, \mathrm{MgCl}_{2}$ 1.2, $\mathrm{KH}_{2} \mathrm{PO}_{4}$ 1.2, $\mathrm{NaHCO}_{3}$ 25.0, NaEDTA 0.026 and $\mathrm{D}(+)$ glucose 5.5; $\mathrm{pH}$ 7.4. Adventitial tissue was carefully removed. Three-millimeter rings were mounted in organ chamber baths filled with the described buffer $\left(37^{\circ} \mathrm{C}\right.$, continuously aerated with $95 \%$ $\mathrm{O}_{2}$ and $5 \%\left(\mathrm{CO}_{2}\right.$ ), were attached to a force transducer, and isometric tension was recorded. The vessels were gradually stretched over $60 \mathrm{~min}$ to a resting tension of $10 \mathrm{mN}$, which was maintained throughout the experiment, and were allowed to equilibrate for a further $30 \mathrm{~min}$. Drugs were added in increasing concentrations in order to obtain cumulative concentration-response curves: $\mathrm{KCl}$ 20 and $40 \mathrm{mmol} / \mathrm{l}$, angiotensin $\mathrm{IL}-1 \mathrm{nmol} / \mathrm{L}$ to $1 \mu \mathrm{mol} / \mathrm{l}$, phenylephrine $1 \mathrm{nmol} / \mathrm{l}$ to $10 \mu \mathrm{mol} / \mathrm{l}$, carbachol $10 \mathrm{nmol} / /$ to $100 \mu \mathrm{mol} / \mathrm{l}$, and nitroglycerin $1 \mathrm{nmol} / \mathrm{l}$ to $10 \mu \mathrm{mol} / \mathrm{l}$. The drug concentration was increased when vasoconstriction or relaxation was completed. Drugs were washed out before the next substance was added. Atherosclerotic lesion development was determined as published previously. Sections of the aortic root were embedded in Tissue Tek O.C.T. embedding medium, snap frozen and stored at $-80^{\circ} \mathrm{C}$. Samples were sectioned on a Leica cryostat and placed on poly-L-lysine coated slides for analysis. Sections were then stained with oil red and analyzed using analysis software measuring the atherosclerotic lesion area in relation to the lumen of the vessel. All animal experiments were performed in accordance with institutional guidelines and the German animal protection law.

\section{Immunohistochemistry}

Samples were sectioned on a Leica cryostat (7-10 $\mu \mathrm{m})$ and placed on poly-L-lysine (Sigma) coated slides for immunohistochemical analysis. For morphometric analyses HE staining was performed according to standard protocols. All sections were examined under a Zeiss Apotom microscope. For morphometric analyses AxioVision software (version 4.5.0) was used. Approximately 10 sections per animal were investigated.

\section{Determination of blood pressure}

Systolic blood pressure (SBP) and heart rate were measured by a computerized tail-cuff system (BP-2000, Visitech Systems, Apex, NC) in conscious animals, as described previously [14]. Mice were trained for 3 consecutive days in the prewarmed tail-cuff device to accustom them to the procedure, followed by additional measurements of SBP and heart rate on 3 consecutive days. On each day of blood pressure determination, 20 measurements were obtained and averaged for each individual animal. The mean values of all 3 days were used for comparisons.

\section{Determination of reactive oxygen species}

Reactive oxygen species (ROS) release in intact aortic segments was determined by L-012 chemi- 
luminescence, as described previously [15]. Aortas were carefully excised and placed in chilled, modified Krebs-HEPES buffer ( $\mathrm{pH} 7.4, \mathrm{NaCl} 99.01$ $\mathrm{mmol} / \mathrm{l}, \mathrm{KCl} 4.69 \mathrm{mmol} / \mathrm{l}, \mathrm{CaCl}_{2} 1.87 \mathrm{mmol} / \mathrm{l}, \mathrm{MgSO}_{4}$ $1.20 \mathrm{mmol} / \mathrm{l}$, NaHEPES $20.0 \mathrm{mmol} / \mathrm{l}, \mathrm{K}_{2} \mathrm{HPO}_{4} 1.03$ $\mathrm{mmol} / \mathrm{l}, \mathrm{NaHCO}_{3} 25.0 \mathrm{mmol} / \mathrm{l}, \mathrm{D}(+)$ glucose 11.1 $\mathrm{mmol} / \mathrm{l})$. Connective tissue was removed and aortas were cut into 2-mm segments. The aortic segments were transferred into scintillation vials containing Krebs-HEPES buffer with $100 \mu \mathrm{mol} / \mathrm{l} \mathrm{L-012}$ and were incubated for $5 \mathrm{~min}$. Chemiluminescence was then assessed over 15 min in a scintillation counter (Lumat LB 9501, Berthold, Bad Wildbad, Germany) in 1 min intervals. The vessel segments were then dried and dry weight was determined. Reactive oxygen species release is expressed as relative chemiluminescence per mg aortic tissue.

\section{Effectiveness and plasma concentration of dabigatran plasma}

Concentrations of dabigatran in mouse plasma samples were measured using the HEMOCLOT ${ }^{\circledR}$ Thrombin Inhibitors assay (Hyphen Biomed, Neuville-sur-Oise, France) according to the manufacturer's instructions with slight modifications. In brief, mouse plasma samples were diluted $1: 8$ using $0.9 \% \mathrm{NaCl}$ solution and $37.5 \mu \mathrm{l}$ of this solution were mixed with $75 \mu \mathrm{l}$ of normal human plas$\mathrm{ma}(\mathrm{NHP})$. After incubation for $1 \mathrm{~min}$ at $37^{\circ} \mathrm{C}, 75 \mu \mathrm{l}$ of a thrombin solution were added to the mixture and clotting times measured using a coagulometer (KC10, Amelung, Lemgo, Germany). For quantification purposes, dabigatran plasma calibrators (Hyphen Biomed), covering a range from 0 to 500 $\mathrm{ng} / \mathrm{ml}$, were run in parallel. All experiments were performed in duplicate. The assay functionally measures the inhibitory effect of dabigatran, originally present in the mouse plasma. In the absence of dabigatran (or other thrombin-inhibiting molecules) in the samples, thrombin added to the mixtures of diluted samples and NHP easily cleaves fibrinogen present in the NHP, leading to formation of a measurable fibrin clot. In the presence of dabigatran in the samples, this effect is inhibited, leading to concentration-dependent prolongation of read-out clotting times.

\section{Statistical analysis}

Values are expressed as mean \pm standard error of the mean. For comparisons between two groups, Student's $t$ test was used.

\section{Results}

\section{Dabigatran elongates thrombin time in $\mathrm{ApoE}^{-/-}$mice}

According to recommendations by Boehringer Ingelheim dabigatran was used at a dose of $10 \mathrm{mg} /$ $\mathrm{kg}$ bodyweight per day. The concentration of dabigatran $(0.372 \pm 0.03 \mu \mathrm{g} / \mathrm{ml})$ in dabigatran-treated animals was determined in blood plasma using the HEMOCLOT ${ }^{\circledR}$ Thrombin Inhibitors assay. The inhibitory effect of dabigatran was illustrated as thrombin time in seconds ( $93.15 \pm 3.5$ s vs. 30.21 \pm 0.9 s) (Figures $1 \mathrm{~A}$ and $\mathrm{B}$ ).

\section{Dabigatran reduces atherosclerotic lesion development in $\mathrm{ApoE}^{-/-}$mice}

Two groups ( $n=10$ per group) of 12 -week old $\mathrm{ApoE}^{-/-}$mice received either high-cholesterol (Western) diet or high-cholesterol diet containing dabigatran $(10 \mathrm{mg} / \mathrm{g})$ for 4 weeks. Drinking water was supplied ad libitum. No animal was lost due to bleeding complications. We observed no differences in body weight ( $32 \pm 3.5 \mathrm{~g}$ vs. $33 \pm 2.8 \mathrm{~g}$ ) between the groups. Treatment with dabigatran resulted in
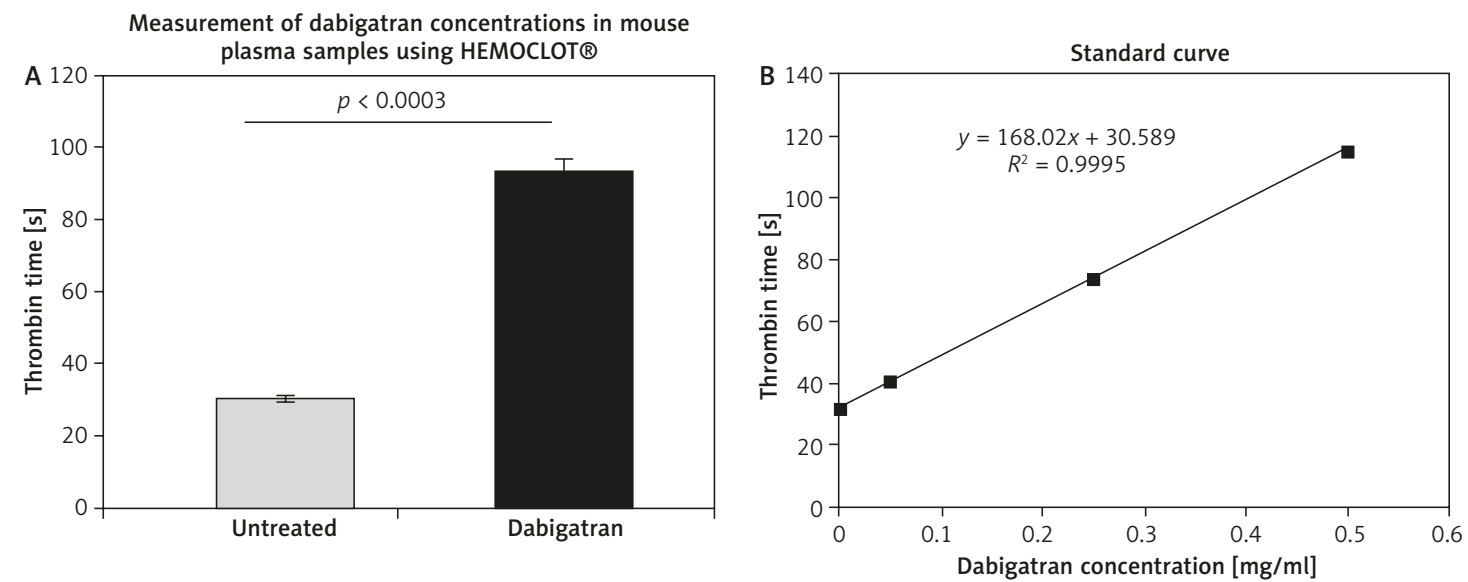

Figure 1. Thrombin time in dabigatran-treated $\mathrm{ApoE}^{-/-}$mice. The inhibitory effect (thrombin time) of dabigatran in mouse plasma samples was measured using the HEMOCLOT® assay (A). Treatment with dabigatran elongated the thrombin time in $\mathrm{ApoE}^{-/-}$mice $(93.15 \pm 3.5 \mathrm{~s}$ vs. $30.21 \pm 0.9 \mathrm{~s})$. For quantification purposes, dabigatran plasma calibrators, covering a range from 0 to $500 \mathrm{ng} / \mathrm{ml}$, were run in parallel (standard curve, B). All experiments were performed in duplicate 

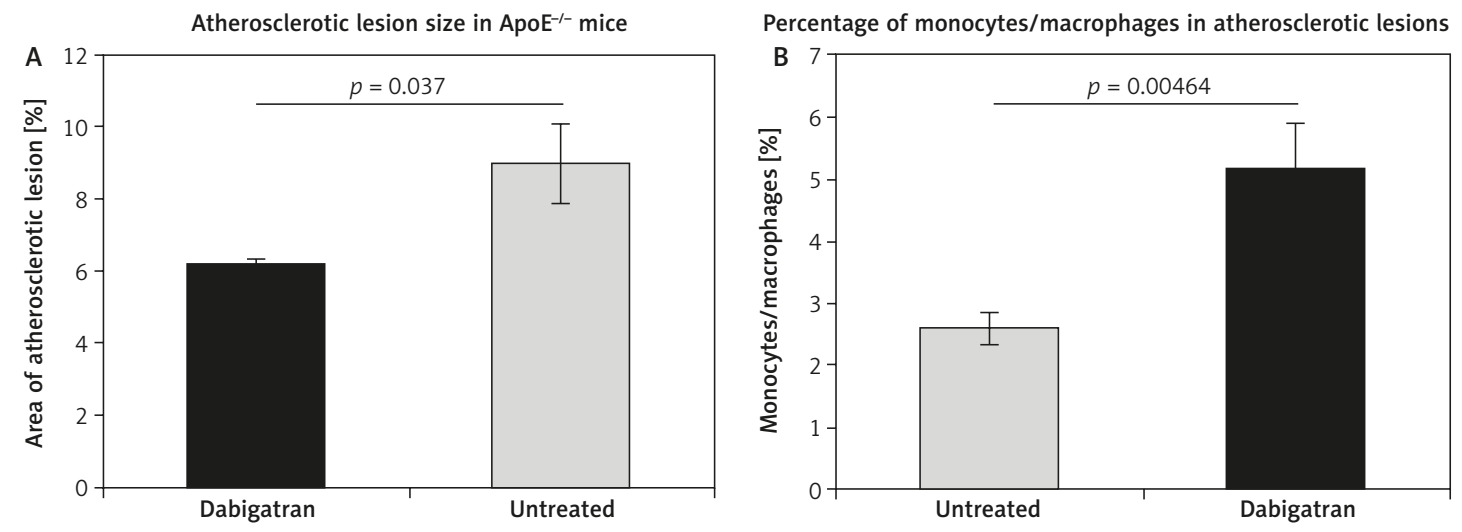

Representative staining of aortic bulb sections

Representative staining of cellular nuclei in aortic bulb sections

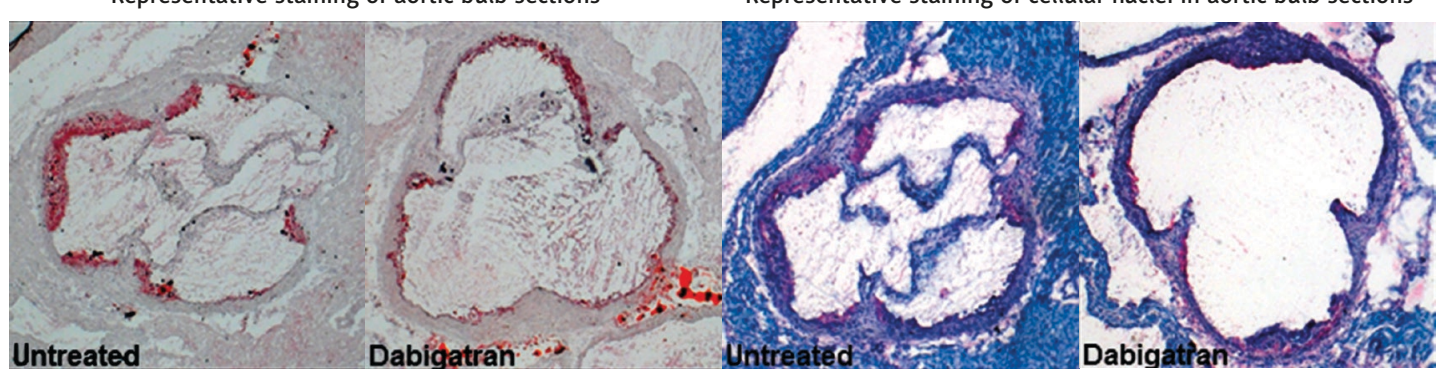

Figure 2. Atherosclerotic lesion size in dabigatran treated $\mathrm{ApoE}^{-/-}$mice. Two groups of 12 -week old ApoE $\mathrm{E}^{-/-} \mathrm{mice}^{\mathrm{re}-}$ ceived either high-cholesterol (Western) diet or high-cholesterol diet containing dabigatran (10 mg/g) for 4 weeks. The animals were then sacrificed and sections of the aortic bulb stained with oil red to determine atherosclerotic lesion size. Treatment with dabigatran resulted in $\mathrm{ApoE}^{-/-}$mice showing a reduction of atherosclerotic lesion size by $31.7 \%(6.2 \pm 0.2 \%$ vs. $9 \pm 1.1 \%)$ (A). In addition, dabigatran treated animals showed a significantly decreased number of nuclei (hematoxylin/eosin staining), indicating a diminished presence of monocytes/macrophages within the atherosclerotic lesions ( $2.59 \pm 0.3 \%$ vs. $5.14 \pm 0.7 \%$ ) (B). The pictures show representative stains of oil red or hematoxylin/eosin

$\mathrm{ApoE}^{-/-}$mice showing a reduction of atherosclerotic lesion size by $31.7 \%(6.2 \pm 0.2 \%$ vs. $9 \pm 1.1 \%)$ (Figure $2 \mathrm{~A}$ ). In addition, slices of the same area of the aortic bulb were stained with hematoxylin/ eosin to determine the number of mononuclear cells within the atherosclerotic lesion area. Dabigatran treated animals showed a significantly decreased number of nuclei, indicating a diminished presence of monocytes/macrophages within the lesions ( $2.59 \pm 0.3 \%$ vs. $5.14 \pm 0.7 \%$ ) (Figure 2 B).

\section{Dabigatran improves endothelial function in $\mathrm{ApoE}^{-/-}$mice}

Sections of the ascending aorta were used to determine endothelial function in organ chamber experiments. Dabigatran treated animals showed significantly improved endothelial function compared to untreated animals (Figure 3 A). Endothelium independent relaxation did not differ between the two groups of animals (Figure $3 \mathrm{~B}$ ). Furthermore, reactive oxygen species generation in aortic rings was determined via L012 luminescence. Treatment with dabigatran resulted in aortas of $\mathrm{ApoE}^{-/-}$mice showing significantly reduced oxidative stress (212 \pm 84 vs. $69 \pm 21 \mathrm{RLU} / \mathrm{s} / \mathrm{mg}$ dry weight) (Figure $3 \mathrm{C}$ ). Blood pressure values deter- mined via tail-cuff measurement did not differ between the groups (Figure $3 \mathrm{D}$ ).

\section{Discussion}

The thrombin inhibitor dabigatran reduces vascular oxidative stress and inflammation and supposedly thereby improves endothelial function and ameliorates atherogenesis in a lipid-driven mouse model of atherosclerosis.

Dabigatran has a predictable pharmacokinetic profile, allowing a fixed-dose regimen without the need for routine coagulation monitoring $[16,17]$. Studies in patients, e.g. stroke prevention in atrial fibrillation, showed a close correlation between plasma dabigatran concentration and the degree of anticoagulant effect [18]. The used Hemoclot ${ }^{\circledR}$ assay is a sensitive diluted thrombin time assay which allows quantitative measurement of dabigatran concentration in plasma, based on inhibition of a constant and defined concentration of thrombin $[17,19,20]$. The used concentration of dabigatran in our study led to increase dabigatran plasma levels. Furthermore, the performed coagulation test revealed a relevant anticoagulatory concentration. The dose used in this study resulted in $\sim 3-4$-fold elevation of thrombin and 


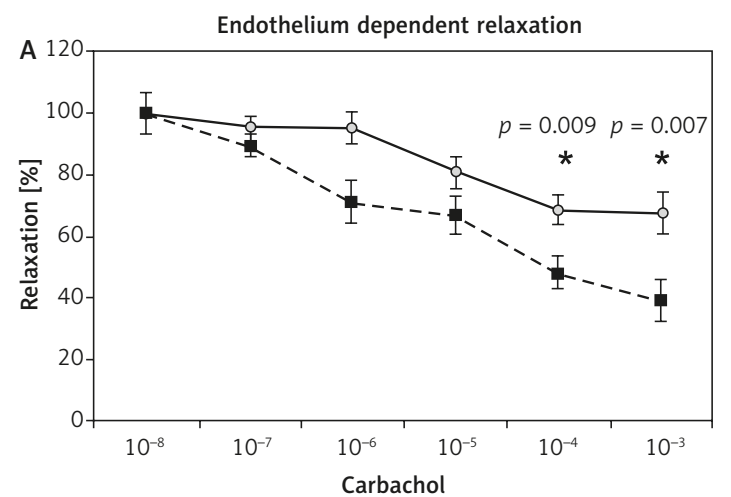

Oxidative stress in aortic segments/Lo12 luminescence

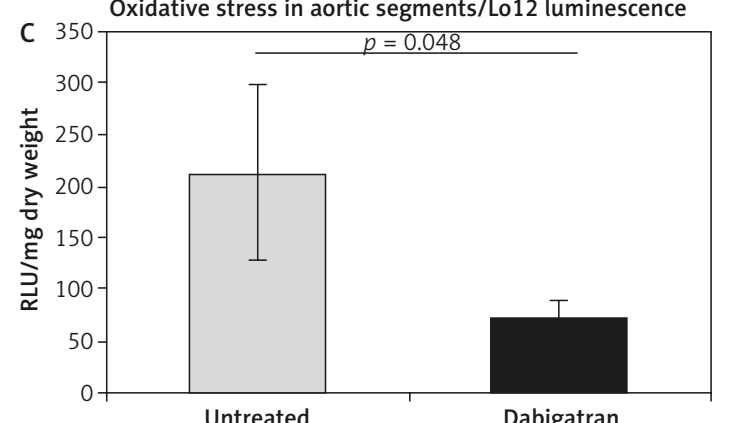

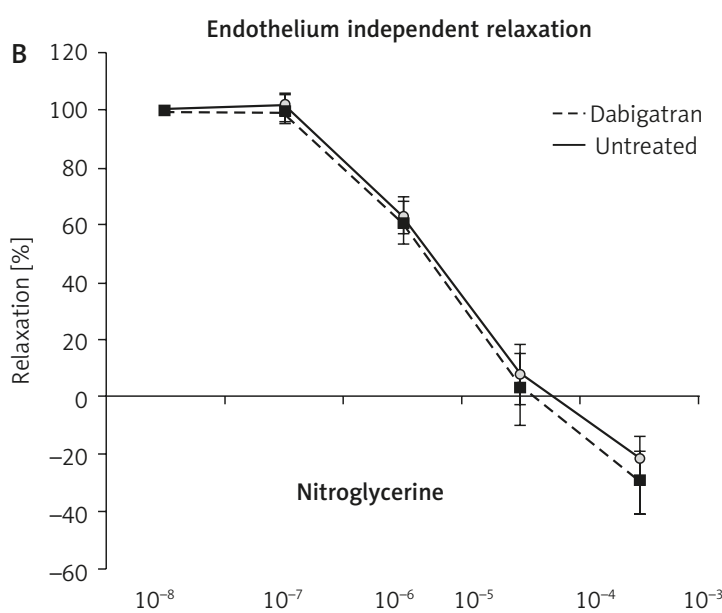

Systolic blood pressure in $\mathrm{ApoE}^{-/-}$mice

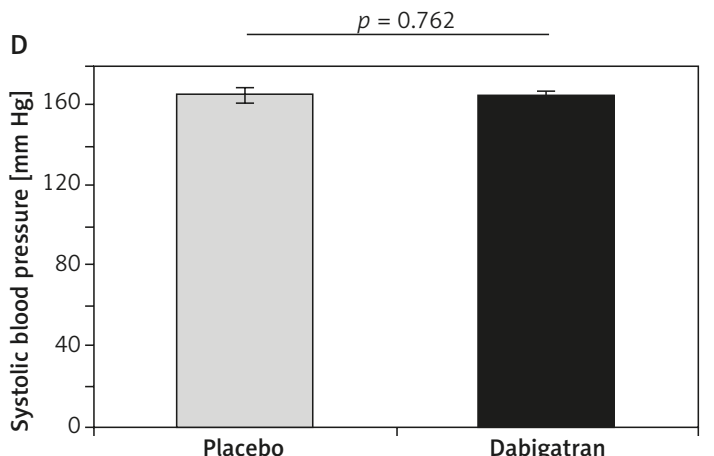

Figure 3. Endothelial function and oxidative stress in dabigatran treated $\mathrm{ApoE}^{-/-}$mice. Dabigatran treated animals showed significantly improved endothelial function compared to untreated animals (A). Endothelium independent relaxation did not differ between the two groups of animals (B). Furthermore, treatment with dabigatran resulted in aortas of ApoE ${ }^{-/-}$mice showing significantly reduced oxidative stress ( $212 \pm 84$ vs. $69 \pm 21 \mathrm{RLU} / \mathrm{s} / \mathrm{mg}$ dry weight) (C). Blood pressure values determined via tail-cuff measurement did not differ between the groups (D)

is consistent with human plasma during dabigatran therapy, where it has also been shown that the thrombin time is more sensitive to dabigatran than aPTT $[17,21]$.

The protease thrombin is intimately involved in procoagulant actions [6], but besides that, thrombin-induced activation of protease-activated receptors (PARs) elicits numerous additional effects on proinflammatory and also vascular cells $[7,9,10]$. The thrombin-dependent impact seems to relate to the state of the target tissue. Whereas thrombin enhances NO synthase activity and endothelial function in healthy tissue [22], the effects in diseased vessel segments are of a different nature and encompass increased production of cytokines and chemokines, VSMC proliferation and contraction as well as enhanced endothelial permeability [4]. Thrombin increases oxidative stress within the vasculature and thereby decreases NO bioavailability [23]. Oxidative stress in turn may induce endothelial dysfunction, plaque growth and destabilization [24]. It is reasonable to assume that enhancement of vascular superoxide production is a key step in thrombin-induced atherogenesis
$[25,26]$. The data presented herein support this idea, since thrombin inhibition via dabigatran significantly reduced free radical excess in the vessel wall. Oxidative stress per se as well as additional thrombin actions renders atherosclerotic lesions in a more pro-inflammatory state $[27,28]$. Expression of various interleukins, adhesion molecules and monocyte chemoattractant protein 1 (MCP-1) is increased in response to thrombin, corresponding to our finding that thrombin inhibition is able to reduce macrophage infiltration in atherosclerotic plaques [29]. Mechanistically this could be explained by direct effects of thrombin on vascular cells, as described [30]. In addition, thrombin and therefore thrombin inhibition as well may directly influence circulating pro-inflammatory cells [27]. This may also be applied to circulating platelets, which are readily influenced via multiple pathways and which are involved in plaque progression and destabilization [31]. Thrombin-induced activation of platelets affects CD 40 ligand, MCP-1, platelet factor-4, RANTES, etc., which can all together contribute to platelet-associated pro-inflammation at vascular lesions [32, 33]. 
This wide array of different and mostly devastating effects of thrombin probably accounts for the atheroprotective effect of dabigatran in $\mathrm{ApoE}^{-/-}$ mice. Our findings are in concert with data showing that deficiency of the natural thrombin inhibitor heparin cofactor II causes accelerated atherosclerosis in $\mathrm{ApoE}^{-/-}$animals, whereas the thrombin inhibitor melagatran ameliorated atherogenesis in the same model [34]. Conversely, a recent publication showed that hypercoagulability mediated either via factor $\mathrm{V}$ Leiden mutation or activated protein $\mathrm{C}$ resistance caused plaque stabilization and positive vascular remodeling compensating for increased plaque growth in $\mathrm{ApoE}^{--}$mice. Hypercoagulability was associated with less macrophage infiltration of plaques, which was reversed by concomitant treatment with low molecular weight heparin. On the basis of in vitro experiments, the authors suggested that thrombin may cause decreased monocyte transmigration [35]. The conflicting results could be caused by different genetic backgrounds of animal models and variable experimental conditions as well as the dissimilarity of the in vitro set-ups. Importantly, the effect of various anticoagulants on vascular tissue may considerably vary.

There is also evidence for clinical relevance of thrombin in atherosclerotic development. Indirect proof comes from several correlation studies showing that markers of a prothrombotic state are associated with increased cardiovascular risk (e.g. prothrombin fragments F1-2, fibrinogen, D-dimer). In addition, trials comparing oral anticoagulation with placebo in patients with peripheral vascular or coronary artery disease showed at least modestly reduced cardiovascular event rates [36]. However, vitamin $\mathrm{K}$ antagonism may essentially differ from direct thrombin inhibition with respect to atheroprotection.

The clinical experience with dabigatran is limited so far. Some studies were performed in patients at risk for venous thrombosis [37]. The RE-LY study showed an excellent effect of dabigatran in patients with atrial fibrillation. The incidence of myocardial infarction was more frequent in the dabigatran treatment group as compared to the warfarin group, but this study was not designed to evaluate vascular endpoints driven by atherosclerosis [30].

In conclusion, the data presented herein show that the direct thrombin inhibitor dabigatran reduces atherosclerotic development in $\mathrm{Apo}^{-/-}$mice and could be therefore of value for atheroprotection.

\section{Acknowledgments} study.

Pingel and Tiyerili contributed equally to this

Simon Pingel and Vedat Tiyerili contributed equally. Vedat Tiyerili (0-109.0033) was supported by BONFOR, University of Bonn, Germany. The excellent technical assistance of Isabel Paez-Maletz and Karin Springmann is greatly appreciated.

\section{Disclosures}

The authors declare that they have no conflict of interest concerning their paper.

Animal chow and Dabigatran (Pradaxa ${ }^{\circledR}$ ) were kindly donated by Boehringer-Ingelheim.

\section{References}

1. Lusis F. Atherosclerosis. Nature 2000; 407: 233-41.

2. Hansson GK. Inflammatory mechanisms in atherosclerosis. J Thromb Haemost 2009; 7 Suppl. 1: 328-31.

3. Esmon CT. The interactions between inflammation and coagulation. Br J Haematol 2005; 131: 417-30.

4. Jawień J, Olszanecki R, Nowak B, Marcinkiewicz J. Apolipoprotein E knockout mice: an experimental model to study inflammatory mechanisms of atherosclerosis and to screen a putative anti-atherogenic properties of drugs. Centr Eur J Immunol 2012; 37: 36-44.

5. Ertek S, Cicero A. Impact of physical activity on inflammation: effects on cardiovascular disease risk and other inflammatory conditions. Arch Med Sci 2012; 8: 794-804.

6. Borissoff J, Spronk HM, Heeneman S, ten Cate H. Is thrombin a key player in the 'coagulation-atherogenesis' maze? Cardiovasc Res 2009; 82: 392-403.

7. Kataoka H, Hamilton JR, McKemy DD, et al. Protease-activated receptors 1 and 4 mediate thrombin signaling in endothelial cells. Blood 2003; 102: 3224-31.

8. Mizuno O, Hirano K, Nishimura J, Kubo C, Kanaide H. Mechanism of endothelium-dependent relaxation induced by thrombin in the pig coronary artery. Eur J Pharmacol 1998; 351: 67-77.

9. Hamilton JR, Cocks TM. Heterogeneous mechanisms of endothelium-dependent relaxation for thrombin and peptide activators of protease-activated receptor- 1 in porcine isolated coronary artery. Br J Pharmacol 2000; 130: 181-8.

10. Hirano K. The roles of proteinase-activated receptors in the vascular physiology and pathophysiology. Arterioscler Thromb Vasc Biol 2007; 27: 27-36.

11. Warfarin Antiplatelet Vascular Evaluation Trial Investigators; Anand S, Yusuf S, Xie C, et al. Oral anticoagulant and antiplatelet therapy and peripheral arterial disease. N Engl J Med 2007; 357: 217-27.

12. Hurlen M, Abdelnoor M, Smith P, Erikssen J, Arnesen $\mathrm{H}$. Warfarin, aspirin, or both after myocardial infarction. N Engl J Med 2002; 347: 969-74.

13. Garcia D, Libby E, Crowther MA. The new oral anticoagulants. Blood 2010; 115: 15-20.

14. Widder JD, Guzik TJ, Mueller CF, et al. Role of the multidrug resistance protein-1 in hypertension and vascular dysfunction caused by angiotensin II. Arterioscler Thromb Vasc Biol 2007; 277: 62-8.

15. Wassmann S, Werner N, Czech T, Nickenig G. Improvement of endothelial function by systemic transfusion of vascular progenitor cells. Circ Res 2006; 99: e74-83.

16. Connolly SJ, Ezekowitz MD, Yusuf S, et al.; RE-LY Steering Committee and Investigators: Dabigatran versus warfarin in patients with atrial fibrillation. N Engl J Med 2009; 361: 1139-51. 
17. Stangier J, Eriksson BI, Dahl OE, et al. Pharmacokinetic profile of the oral direct thrombin inhibitor dabigatran etexilate in healthy volunteers and patients undergoing total hip replacement. J Clin Pharmacol 2005; 45: 555-63.

18. Avecilla ST, Ferrell C, Chandler WL, Reyes M. Plasma-diluted thrombin time to measure dabigatran concentrations during dabigatran etexilate therapy. Am J Clin Pathol 2012; 137: 572-4.

19. Harenberg J, Giese C, Marx S, Krämer R. Determination of dabigatran in human plasma samples. Semin Thromb Hemost 2012; 38: 16-22.

20. Wienen W, Stassen JM, Priepke H, Ries UJ, Hauel N. In-vitro profile and ex-vivo anticoagulant activity of the direct thrombin inhibitor dabigatran and its orally active prodrug dabigatran etexilate. Thromb Haemost 2007; 98: 155-62.

21. Stangier J, Rathgen K, Stähle H, Gansser D, Roth W. The pharmacokinetics, pharmacodynamics and tolerability of dabigatran etexilate, a new oral direct thrombin inhibitor, in healthy male subjects. Br J Clin Pharmacol 2007; 64: 292-303.

22. Gudmundsdóttir IJ, Lang NN, Boon NA, et al. Role of the endothelium in the vascular effects of the thrombin receptor (protease-activated receptor type 1) in humans. J Am Coll Cardiol 2008; 51: 1749-56.

23. Rudolph V, Rudolph TK, Schopfer FJ, et al. Bivalirudin decreases NO bioavailibility by vascular immobilization of myeloperoxidase. J Pharmacol Exp Ther 2008; 327 : 324-31.

24. Harrison D, Griendling KK, Landmesser U, Hornig B, Drexler $\mathrm{H}$. Role of oxidative stress in atherosclerosis. Am J Cardiol 2003; 91; 7A-11A.

25. Görlach A, Diebold I, Schini-Kerth VB, et al. Thrombin activates the hypoxia-inducible factor-1 signaling pathway in vascular smooth muscle cells: role of the p22(phox)containing NADPH oxidase. Circ Res 2001; 89: 47-54.

26. Wachowicz B, Olas B, Zbikowska HM, Buczyński A. Generation of reactive oxygen species in blood platelets. Platelets 2002; 13: 175-82.

27. Martorell L, Martínez-González J, Rodríguez C, Gentile M, Calvayrac O, Badimon L. Thrombin and protease-activated receptors (PARs) in atherothrombosis. Thromb Haemost 2008; 99: 305-15.

28. Mieczkowska J, Mosiewicz J, Barud W, Kwaśniewski W. Changes in the activity of connective tissue matrix enzymes in the metabolic syndrome. Arch Med Sci 2011; 7: 634-41.

29. Colotta F, Sciacca FL, Sironi M, Luini W, Rabiet MJ, Mantovani A. Expression of monocyte chemotactic protein-1 by monocytes and endothelial cells exposed to thrombin. Am J Pathol 1994; 144: 975-85.

30. Maruyama I, Shigeta K, Miyahara H, et al. Thrombin activates NF-kappa B through thrombin receptor and results in proliferation of vascular smooth muscle cells: role of thrombin in atherosclerosis and restenosis. Ann N Y Acad Sci 1997; 811: 429-36

31. May AE, Seizer P, Gawaz M. Platelets: inflammatory firebugs of vascular walls. Arterioscler Thromb Vasc Biol 2008; 28: s5-10.

32. Henn V, Slupsky JR, Gräfe M, et al. CD40 ligand on activated platelets triggers an inflammatory reaction of endothelial cells. Nature 1998; 391: 591-4.

33. von Hundelshausen $P$, Weber KS, Huo Y, et al. RANTES deposition by platelets triggers monocyte arrest on inflamed and atherosclerotic endothelium. Circulation 2001; 103: 1772-7.
34. Bea F, Kreuzer J, Preusch M, et al. Melagatran reduces advanced atherosclerotic lesion size and may promote plaque stability in apolipoprotein E-deficient mice. Arterioscler Thromb Vasc Biol 2006; 26: 2787-92.

35. Seehaus S, Shahzad K, Kashif M, et al. Hypercoagulability inhibits monocyte transendothelial migration through protease-activated receptor-1-, phospholipase-Cbeta-, phosphoinositide 3-kinase-, and nitric oxide-dependent signaling in monocytes and promotes plaque stability. Circulation 2009; 120: 774-84.

36. Mohler ER 3rd. Atherothrombosis: wave goodbye to combined anticoagulation and antiplatelet therapy? N Engl J Med 2007; 357: 293-6.

37. Garcia D, Libby E, Crowther MA. The new oral anticoagulants. Blood 2010; 115: 15-20. 